\title{
Large-Scale Dairy Operations: Assessing Concerns of Neighbors About Quality-of-Life Issues
}

\author{
H. D. Schmalzried ${ }^{1}$ and L. F. Fallon Jr. \\ Department of Public and Allied Health, Bowling Green State University, Bowling Green, $\mathrm{OH} 43403$
}

\begin{abstract}
An increasing number of large-scale dairy operations are being built across the United States. Many of the neighbors of proposed large-scale dairy operations are upset at how dairies will affect their quality of life. We assessed the intensity of these concerns at least $1 \mathrm{yr}$ after 2 new dairies began operation. Surveys $(\mathrm{n}=275)$ were mailed to collect data. The opinions $(\mathrm{n}=64)$ of those living close to large-scale dairy operations were compared with those of individuals in control groups $(\mathrm{n}=38)$ living at least $8 \mathrm{~km}$ away. There were no significant differences between groups and no complaints had been received, suggesting that quality-of-life issues are specious with regard to properly managed largescale dairy operations with 700 or fewer cows. We recommend the following for future policy decisions: Largescale dairy operations should be located in areas where there are few, if any, current neighbors and where future residential development is least likely to occur. Conducting longitudinal studies at intervals of 3 and $5 \mathrm{yr}$ of operation involving these same issues could determine whether any changes in reaction have occurred since this study.
\end{abstract}

Key words: large-scale dairy operation, odor, drinking water quality, real estate value

\section{INTRODUCTION}

Major animal agriculture sectors in the United States are rapidly transitioning into large-scale animal production operations, also known as confined animal feeding operations (CAFO). The changing nature of livestock production during the 1990s has been associated with the rapid growth of CAFOs, especially in the pork, dairy, and poultry industries (Cole et al., 2000). Confined animal feeding operations achieve economies of scale through specialization, their larger size, and close confinement that allows animals to be concentrated into

Received September 15, 2006.

Accepted November 28, 2006.

${ }^{1}$ Corresponding author: hschmal@bgsu.edu small areas (US Environmental Protection Agency, 2006). Nationally, large-scale swine operations have received the most attention.

Increasing numbers of large-scale dairy operations are being built in the Midwest. Large-scale dairies are generally viewed as undesirable neighbors even before they move in. Media reports (Feehan, 2001; Magers, 2001; Pugh, 2002) from public meetings discussing perceived problems with large-scale dairy operations have revealed 4 primary concerns: 1) declining property values, 2) a decrease in the quality of drinking water, 3) concerns about odors produced by manure, and 4) fly infestation problems. Emotions often run high at these public meetings, with fear and anger over concerns about quality-of-life issues and decreased property values often being strongly voiced.

No reports were found in the literature on the opinions of close neighbors about quality-of-life issues after they had lived near a newly established, large-scale dairy operation for at least $1 \mathrm{yr}$. We conducted this study to capture the opinions of those living near a newly established large-scale dairy operation and to understand whether their quality of life has been affected. A large-scale operation was defined as having more than 600 dairy cows. A herd size of 600 cows was chosen because large-scale dairy operations with fewer than 700 animals are unregulated in Ohio. New operators generally prefer to start out below the regulatory threshold. The 4 quality-of-life issues used were related to concerns commonly associated with large-scale dairy operations (i.e., property values, drinking water quality, odors, and flies). Knowing the perceptions of people living near large-scale dairy operations related to quality-of-life issues should provide useful information for land-use planners and risk managers. Managers of risk are identified as government and environmental agencies, farm operators, and dairy development companies (Whittington and Warner, 2006). Risk managers must have objective knowledge of the concerns of neighbors about living near a large-scale dairy operation. This information can assist them in addressing concerns and can help them determine whether more stringent standards should be applied when future large-scale dairy 
operations are being proposed. Each of the dairies included in this study had just $<700$ cows.

We surveyed neighbors living within $1.6 \mathrm{~km}$ of 2 new large-scale dairy operations in northwestern Ohio to assess the intensity of their opinions about quality-oflife issues. The same survey was administered to other groups of individuals living more than $8 \mathrm{~km}$ away from the new dairy operations. One group of people was similar, based on population density (i.e., rural); these individuals were involved in agriculture but did not live near a large-scale dairy operation. Another group lived in an urban area. All of these individuals were surveyed to compare their opinions related to living near the new large-scale dairy operations by using objective data. Examination of the differences between those affected and those not affected was intended to help educators and risk managers differentiate real concerns from those perpetuated by myth or the media.

\section{MATERIALS AND METHODS}

\section{Sample}

The study was conducted approximately $1 \mathrm{yr}$ after 2 new large-scale dairies began operation. Confidential questionnaires were mailed to 108 residents living within a $1.6-\mathrm{km}$ radius of the 2 large-scale dairy operations. Sixty-four residents (38 downwind and 26 upwind) completed and returned the questionnaire, for a response rate of $59.3 \%$. Confidential questionnaires were mailed to 47 members of a rural group of residents living in a topologically similar area but not near a large-scale dairy operation. Nineteen members of this group completed and returned the questionnaire, for a response rate of $40.4 \%$. Confidential questionnaires were also mailed to 120 randomly selected residents of a small city located near the study area (the urban group). Nineteen urban residents completed and returned the questionnaire, for a response rate of $15.8 \%$. A total of 4 responses were missing on different returned questionnaires. All returned questionnaires were usable and were included in the subsequent analysis.

\section{Instrument}

The 13-item questionnaire (Table 1) asked residents their opinions on whether a person's quality of life was affected by living near a large-scale dairy operation. Participants were asked to provide responses by circling their preferences on a 5-point scale. Nine questions identified respondents' impressions regarding their quality of life. Four questions and color-coding of the questionnaires yielded 5 pieces of demographic data per respondent. The demographic information collected included the percentage of income derived through agriculture, the likelihood of the respondent selling his or her home within the next $5 \mathrm{yr}$, whether the respondent raised livestock, the age and gender of the respondent, and whether the respondent lived upwind or downwind from a dairy operation (color-coded paper). Self-addressed, stamped envelopes were provided in which to return the questionnaires. Responses were coded and entered into a database for analysis.

\section{Statistics}

Frequencies and cross-tabulations were conducted on the coded data. The number of residents who responded to a particular question was used to calculate percentages. Chi-squared tests of independence were conducted to examine the association between categorical dependent variables and demographic variables.

\section{RESULTS}

\section{Response Rates Among Residents Living Close to Dairies}

Our study encompassed 4 different groups of residents, with grouping based on residents' proximity to a large-scale dairy operation. All respondents received a stamped and preaddressed envelope with the same 13-item questionnaire, which took only a few minutes to complete. Response rates varied. One apparent observation was that those who were affected most by the issue were more likely to respond to a survey about that issue. The further away residents lived from the large-scale dairy operation, the less interest they seemed to have in responding. Residents in the downwind group of individuals living nearby demonstrated the most passion about their concerns by having the highest group response rate $(66.7 \%)$. The response rate of the upwind group (51.0\%) was not as large as that of the downwind group. Living upwind, these residents were not exposed to as many odors as the downwind group. The distant rural group had a response rate (40.4\%) that was not as high as those living within 1.6 $\mathrm{km}$ of the large-scale dairy. The response rate from the urban group (15.8\%) seemed to reflect apathy. Although urban dwellers may not link dairy farming activities with milk production, we did not test their knowledge of this association.

\section{Differences Between Upwind and Downwind Neighbors}

Among people living near a large-scale dairy operation, no significant differences in responses $(P>0.05)$ 
Table 1. Instrument used to measure impact of a large-scale dairy farm operation on quality of life

A range of opinions exist about whether a person's quality of life is affected by living near a large dairy farm (defined as 600 plus cows). Please complete the survey by circling the response that best reflects your knowledge or opinion.

\section{(Please circle your answer)}

1. The value of a person's property is affected by living near a large dairy farm

Strongly disagree Disagree Neutral Agree $\quad$ Strongly agree

2. The impact on property value is

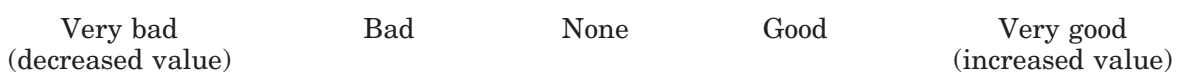

3. The quality of drinking water is affected by living near a large dairy farm

Strongly disagree Disagree Neutral Agree $\quad$ Strongly agree

4. The impact on the quality of drinking water is

\begin{tabular}{|c|c|c|c|}
\hline $\begin{array}{l}\text { Very bad } \\
\text { educed quality) }\end{array}$ & $\mathrm{Bad}$ & None & Good \\
\hline
\end{tabular}

5. The smell of cow manure is a concern for people living near a large dairy farm

Strongly disagree Disagree Neutral Agree $\quad$ Strongly agree

6. I would rate smell from a large dairy as

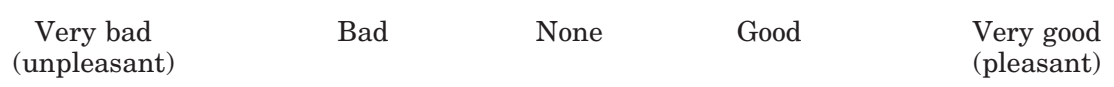

7. Flies are a nuisance for persons living near a large dairy farm

Strongly disagree Disagree Neutral Agree Strongly agree

8. I would rate the fly problem from living near a large dairy farm as

$\begin{array}{ccccc}\begin{array}{c}\text { Very bad } \\ \text { (increase in flies) }\end{array} & \text { Bad } & \text { None } & \text { Good } & \begin{array}{c}\text { Very good } \\ \text { (decrease in flies) }\end{array}\end{array}$

9. I am likely to sell my home within the next $5 \mathrm{yr}$

Strongly disagree Disagree Neutral Agree Strongly agree

10. My household derives approximately this percentage of its income through agriculture
$0-19 \%$
$20-39 \%$
$40-59 \%$
$60-79 \%$
$80+\%$

11. My household raises some livestock

Yes No

12. My age category is
Under 30
$31-40$
$41-50$
$51-64$
Over 65

13. I am:
Female
Male

Thank you for your time and opinions. Please place your completed survey in the preaddressed, stamped envelope and mail it today. No postage is needed.

were found between the upwind and downwind groups. Of the respondents living near a large-scale dairy,

1. $20.3 \%$ derived at least $40 \%$ of their income from agriculture;

2. $17.2 \%$ raised some livestock;

3. $64.1 \%$ were $51 \mathrm{yr}$ or older; and

4. $70.3 \%$ were male and $29.7 \%$ were female.

\section{Differences Between Rural and Urban Groups}

There were no significant differences in responses $(P$ $>0.05$ ) between the distant rural and urban control groups. Among all respondents not living near a largescale dairy operation,

1. $13.2 \%$ derived at least $40 \%$ of their income from agriculture; 
Table 2. Comparison of issues between those living near and those living far from a large-scale dairy operation

\begin{tabular}{lccc}
\hline & $\begin{array}{c}\text { Near, } \\
\text { no. (\%) }\end{array}$ & $\begin{array}{c}\text { Far, } \\
\text { no. (\%) }\end{array}$ & $P^{1}$ \\
\hline Attribute (question no.) & $54(87.1)$ & $32(84.2)$ & NS \\
Property value affected (1) & $53(82.8)$ & $34(89.5)$ & NS \\
Property values decrease (2) & $16(25.0)$ & $9(23.7)$ & NS \\
Sell home within 5 yr (9) & $30(46.9)$ & $26(68.4)$ & NS \\
Drinking water affected (3) & $44(68.8)$ & $28(75.7)$ & NS \\
Drinking water quality reduced (4) & No & No \\
Concerns about smell of manure (5) & $59(92.2)$ & $30(78.9)$ & NS \\
Manure smell unpleasant (6) & $52(81.3)$ & $23(60.5)$ & NS \\
Flies are a nuisance (7) & $45(70.3)$ & $32(84.2)$ & NS \\
Fly problem is bad (8) & $41(64.0)$ & $29(76.3)$ & NS \\
\hline
\end{tabular}

${ }^{1} \mathrm{NS}=$ not significant; $P>0.05$.

2. $10.8 \%$ reported raising some livestock;

3 . $65.7 \%$ were 51 yr or older; and

4. $63.2 \%$ were male and $36.8 \%$ were female.

\section{Differences Between Near and Far Respondents}

The upwind and downwind respondents were combined into a single group, referred to as those "living near" large-scale dairy operations. Distant rural and urban respondents were combined into a single group, referred to as those "living far" from large-scale dairies. Respondents living near large-scale dairy operations, as well as rural and urban residents living far from a CAFO, expressed concern about quality-of-life issues. Their concerns included problems with loss of real estate value, degradation of drinking water quality, odors, and flies caused by the presence of a CAFO. Table 2 provides a comparison of issues between those living near and those living far from a large-scale dairy operation. A summary of these results showed that,

1. $82.8 \%$ of those living near and $89.5 \%$ of those living far from a large-scale dairy operation believed property values had decreased;

2. $68.8 \%$ of those living near and $75.7 \%$ of those living far from a large-scale dairy believed drinking water quality was affected;

3. $92.2 \%$ of those living near and $78.9 \%$ of those living far from a large-scale dairy believed the odor of manure was a concern; and

4. $70.3 \%$ of those living near and $84.2 \%$ of those living far from a large-scale dairy believed flies were a nuisance.

\section{DISCUSSION}

Questionnaires were sent to 2 groups of residents to assess the accuracy and intensity of their opinions regarding 4 quality-of-life issues associated with living near a large-scale dairy operation. The 2 groups in- cluded 1) residents living within $1.6 \mathrm{~km}$ of a large-scale dairy, and 2) control groups of residents living $\geq 8 \mathrm{~km}$ from a large-scale dairy.

\section{Quality-of-Life Concerns Not Based on Reality}

We found that the accuracy of quality-of-life concerns that were expressed about living near a large-scale dairy operation was not based on reality. According to realtors familiar with the study area, real estate transfers within $16.1 \mathrm{~km}$ of the 2 large-scale dairy operations had not shown declining values since the dairies became operational. Where real estate values had appreciated, the rate of increase for land near to and distant from a CAFO was approximately the same. No complaints about drinking water quality, odors, or fly infestations had been verified by the relevant governmental risk managers concerning either large-scale dairy operation included in the study. Furthermore, there were no differences in the intensity of beliefs between those living near and those living far from a large-scale dairy. All raised strong objections to the new large-scale dairies and felt that a CAFO affected their quality of life. Based on our analysis of data obtained after approximately 1 yr of operation, the 4 quality-oflife issues were specious.

In many instances, the reactions of neighbors to a CAFO moving into their communities have been contentious. For example, in a Google inquiry on August 8,2006 , using the search terms "neighbors," "concerns," and "confined animal feeding operations," 18,500 sites were listed. In the present study, concerns were vocalized by only a few individuals, who may or may not have lived nearby a proposed large-scale dairy operation. The opinions of the majority are not known. Differences in response rates between the original 2 groups indicated that the more (or less) likely people were to be affected by an issue, the more (or less) likely they were to respond to questions about it. The urban group responded in a manner similar to voter turnout at some elections: If the issue did not affect them, they did not bother to vote (Tolbert et al., 2001).

\section{CONCLUSIONS}

This study provided some clarification regarding the intensity of opinions that have been expressed about 4 quality-of-life concerns often associated with living near large-scale dairies. We found that whether people lived in close proximity (upwind or downwind) or $8 \mathrm{~km}$ away (in a rural or an urban area) did not matter; the opinions of residents about quality-of-life issues were similar. The opinions of the individuals we surveyed were not supported by objective data (property values, water- 
quality issues, odors, and fly nuisances). Property values have not declined, water quality has not been affected, odor problems have not been documented, and no fly nuisance complaints have been received. Also, odors usually disperse or dissipate after traveling 8 $\mathrm{km}$, and they do not travel upwind. Current and future climatic and production changes could result in more objective reactions from those living near the largescale dairies. Furthermore, some conditions could have cumulative effects that may not be apparent after only $1 \mathrm{yr}$ of operation.

\section{Recommendations}

The emotions involved in finding sites to locate largescale dairy operations appear to be similar to those of obtaining sites for airports, nuclear power plants, and sanitary landfills; people do not want one in their backyard. Large-scale dairy operations should be located in areas where there are few, if any, current neighbors and where future residential development is least likely to occur. Conducting longitudinal studies involving these same issues at intervals of 3 and 5 yr of operation could determine whether any changes in reaction have occurred since this study.

\section{REFERENCES}

Cole, D., L. Todd, and S. Wing. 2000. Concentrated swine feeding operations and public health: A review of occupational and community health effects. Environ. Health Perspect. 108:685-699.

Feehan, J. 2001. Arrival of dairy farm fuels fear of division. Toledo Blade (Dec. 31):B1, B2.

Magers, K. R. 2001. Proposed megafarm raises local concerns. Northwest Signal (May 8):A1, A2.

Pugh, D. 2002. Megafarm debate begins in our area. Buckeye (Apr. 17):1.

Tolbert, C. J., J. A. Grummel, and D. A. Smith. 2001. The effects of ballot initiatives on voter turnout in the American states. Am. Politics Res. J. 29:625-648.

US Environmental Protection Agency. 2006. Ag 101: Dairy Production. Available: http://epa.gov/agriculture/ag101/dairy.html Accessed Aug. 2, 2006.

Whittington, M. S., and K. J. Warner. 2006. Large scale dairies and their neighbors: A case study of the perceived risk in two counties. J. Extension 44(1), Article 1FEA4. Online. Available: http:// www.joe.org/joe/2006february/a4.shtml Accessed Aug. 2, 2006. 